\title{
ÉTICA NA PESQUISA COM SUJEITOS HUMANOS: Aspectos a destacar para investigadores iniciantes
}

\author{
Ethics in researchs involving human beings: \\ Aspects for being detached for beginner investigators
}

\author{
Ana Paula Araújo de Freitas ${ }^{a}$, Nicia Luíza Duarte da Silveira ${ }^{b}$
}

\begin{abstract}
^Acadêmica de Psicologia da Universidade Federal de Santa Catarina. Florianópolis, SC - Brasil, e-mail: anapaulaafreitas@hotmail.com bProfessora do Departamento de Psicologia da Universidade Federal de Santa Catarina - Doutora em Psicologia Experimental (IPUSP), Depto. de Psicologia, Câmpus Trindade, Florianópolis, SC - Brasil, e-mail: nicia@cfh.ufsc.br
\end{abstract}

\section{Resumo}

A ética é um tema bastante suscitado em discussões sobre a atuação profissional bem como as questões envolvendo a cidadania. Atualmente essa discussão estende-se às pesquisas científicas e em especial às realizadas com sujeitos humanos. A literatura pertinente coloca que, para responder sua questão primordial, o pesquisador deve dar garantia total aos seus sujeitos para que estes não sofram qualquer tipo de constrangimento. A presente investigação teve por objetivo verificar o que é relevante em pesquisas realizadas na área da Psicologia. Para tal, foram entrevistados nove professores pesquisadores do departamento em questão, usando-se um roteiro para entrevista com quatro questões orientadoras. As respostas obtidas apontam unanimidade a cerca de princípios éticos básicos e indicam que entre os principais aspectos apontados estão o sigilo das informações; o consentimento livre e informado; a devolução da pesquisa e a divulgação das informações e dos dados encontrados. Outro destaque deve ser feito à indicação de que os códigos de ética disponíveis são bastante genéricos, como a Resolução 196, e pouco específicos em relação à pesquisa psicológica, bem como claros para o pesquisador experiente e pouco esclarecedor para os inexperientes. Estes resultados confirmam a importância de conscientizar os profissionais da área da Psicologia, bem como os estudantes da área, para o papel da ética, não só na pesquisa, mas como subsídio às relações diárias das pessoas.

Palavras-chave: Ética; Pesquisa; Pesquisadores iniciantes. 


\begin{abstract}
Ethical is a subject that have been suscitated several times in discussions about the professional performance, as well as the questions involving the citizenship. Currently this discussion extends to the scientific research, particulary on those accomplished with human subjects. Pertinent literature says that, to answer its primordial question, the researcher must give total guarantee to its subjects so these do not suffer any kind of embarrassment. The present inquiry had the objective to verify what is relevant about research carried through in the area of Psychology. For such, nine researchers that are also professors at the department mentioned before had been interviewed. The autors utilized a script for interview with four orienting questions. The gotten answers point unamimity about basic ethical principles, and indicate that on the main pointed aspects are the secrecy of the information; the free and informed assent; the devolution of the research and the spreading of the information and the joined data. Another prominence must be made to the indication of that the available codes of ethics are sufficiently generic, as Resolution 196, and little specific about the psychological research, as well as, clear for the experienced researcher and little enlightening for the inexperienced ones. These results confirm the importance to professionals of the area of Psychology adquire knowledge, as well as, the students of the area, for the part of the ethics, not only in the research, but as subsidy to the daily relationships of the people.
\end{abstract}

Keywords: Ethics; Research; Beginner researchers.

\section{INTRODUÇÃO}

Tendo em vista a importância da ética no processo de investigação e as dificuldades existentes para concretizar nas atividades envolvidas ao longo do processo de pesquisa, medidas que resguardem a identidade e o bemestar dos sujeitos humanos nela envolvidos, bem como a urgência de discussão com aqueles que se iniciam na área da pesquisa, propôs-se a presente pesquisa, na qual foram abordados, por meio de um roteiro de entrevista composto por quatro questões orientadoras, nove docentes do departamento de Psicologia da Universidade Federal de Santa Catarina, com o objetivo de levantar pontos relevantes sobre a ética com a pesquisa com seres humanos.

Conforme Araújo (2003, citado por Palácios, Rego e Schramm, 2002), muitos pesquisadores acreditavam que a firme determinação de fazer o bem, a integridade de caráter e o rigor científico eram suficientes para promover a ética em suas pesquisas. Esta concepção já não é mais consenso. O grande desenvolvimento e a crescente inclusão de novas tecnologias no campo de cuidados em saúde; a difusão do conhecimento científico por meio dos meios de comunicação social tradicionais e, particularmente, com a internet, bem como a ampliação dos movimentos sociais em defesa dos direitos individuais e da coletividade, fizeram com que a discussão sobre a ética aplicada à saúde passasse a ter como interlocutores filósofos, teólogos, juristas, sociólogos e, sobretudo, os cidadãos, seja como usuários do sistema de saúde, ou como sujeitos participantes das pesquisas científicas.

Segundo Pessini e Barchifontaine (2000, p. 140), o termo pesquisa refere-se a uma classe de atividades cujo objetivo é desenvolver ou contribuir para o conhecimento generalizável. Este se caracteriza pela elaboração de princípios, leis, relações e/ou teorias, como também no acúmulo de informações sobre as quais está baseado, que possam ser corroboradas por métodos científicos aceitos por meio de observação e inferência. Em relação a pesquisas com seres humanos, os mesmos autores completam:

\footnotetext{
Pesquisas com seres humanos incluem estudos de um processo fisiológico, bioquímico ou patológico, ou resposta a uma intervenção específica - seja física, química ou psicológica - em pacientes ou participantes sadios; testes controlados de medidas diagnósticas, preventivas ou terapêuticas em grupos maiores de pessoas, projetados para demonstrar uma
} 
resposta generalizável específica àquelas medidas, comparada com os limites da variação biológica individual; estudos projetados para determinar as conseqüências, para indivíduos e comunidades de medidas terapêuticas ou preventivas específicas e estudos relativos a comportamentos humanos ligados à saúde em uma gama de circunstâncias e ambientes.

Lidar com pessoas não é uma tarefa das mais fáceis. Existe uma série de aspectos que devem ser levados em conta e respeitados quando se entra numa relação com o outro. Fazer pesquisa com seres humanos, da mesma forma, implica estabelecer uma relação dentro de certos parâmetros, que podem agravar estas tensões sob alguns aspectos, fazendo com que esta não seja uma situação das mais confortáveis para seus protagonistas, sejam eles o pesquisador ou o pesquisado. Dessa forma, como expressa Zanella (2003, p. 43), há "necessidade do compromisso dos pesquisadores, independente do objeto, dos objetivos e do método delineado em suas investigações, tanto o que investigam - com os usos que serão feitos desses conhecimentos quanto com quem investigam". Dito de forma mais direta, é necessário, portanto, tomar uma série de precauções a fim de que o participante não sofra conseqüências negativas por sua participação em uma pesquisa, sofrendo o menor desconforto possível no âmbito biopsicossocial.

No passado, questões relativas a experimentos com seres humanos geravam uma série de discussões: o que poderia ser feito, o que era considerado humano ou desumano, o que era permitido e o que não era, se era ético ou não. Para solucionar tais problemas, foram criadas maneiras de formalizar e legalizar os procedimentos que poderiam ser utilizados e as atitudes que deveriam ser tomadas para que fosse viável lidar com seres humanos em pesquisas. Dentre elas, conforme Pessini e Barchifontaine (2000, p. 141), estão os Comitês de Ética, a Declaração de Nuremberg, de 1947, que enfatiza, sobretudo, o "consentimento voluntário do participante da pesquisa" e a Declaração de Helsinque, publicada em 1964, pela Associação Médica Mundial.

De maneira geral, a ética vem delimitar as atividades daqueles que buscam avanço científico em determinadas áreas, os pesquisadores, a fim de que estes respeitem a integridade das pessoas que se dispuseram a participar na pesquisa, em todos os âmbitos nos quais a pesquisa possa vir a influenciar. Mas o que se pode definir como ética?

Segundo o dicionário Aurélio (Ferreira, 2004, p. 842), ética é definida como o "estudo dos juízos de apreciação referentes à conduta humana suscetível de qualificação do ponto de vista do bem e do mal, seja relativamente a determinada pela sociedade, seja de modo absoluto". Em relação à pesquisa, Costa e Diniz (2001, p. 110) ressaltam que da mesma forma que ela é necessária, também pode tornar-se problemática do ponto de vista ético e social. E complementam:

Todavia, a partir do momento em que a medicina [e também, porque não dizer, as outras áreas] passou a incorporar ciência e tecnologia, a humanidade tomou conhecimento de que ambas tinham origens nos laboratórios, nos experimentos com animais e nas pesquisas com seres humanos com a participação das pessoas nas pesquisas, era indispensável lhes assegurar, por meio do consentimento livre e esclarecido, o princípio da autodeterminação.

Ao longo da História, de acordo com Hossne e Vieira (1995), experimentações envolvendo seres humanos têm sido realizadas com diferentes padrões de qualidade e ética. A literatura relata vários exemplos de estudos e pesquisas realizados com seres humanos que chocaram, e ainda chocam, a humanidade. Nesses casos, a ausência de mecanismos de controle, fundamentados em critérios éticos e morais, permitiu abusos mediante experimentos e a cobaização do ser humano.

Beecher (1966), em sua época, já argumentava que era inaceitável que as pessoas fossem tratadas como meros objetos e continuassem a não ser informadas sobre os riscos a que estavam sujeitas quando participavam das pesquisas. O mesmo autor ainda ressalta a importância do consentimento livre e esclarecido e recomenda que se evite, tanto quanto possível, qualquer dano que possa ser previsto à integridade do sujeito da pesquisa.

De acordo com Palácios et al. (2002), os abusos cometidos em nome do Estado e da Ciência, apurados e denunciados mundialmente em 1947, no relatório final do Tribunal Internacional de Nuremberg, levaram à elaboração do primeiro código 
de conduta em pesquisas, internacionalmente aceito - o Código de Nuremberg. A investigação histórica revela várias situações em que a ética não foi respeitada, às vezes, nem sequer cogitada. Deslizes éticos, afirmam Hossne e Vieira (1995), ocorriam antes da elaboração deste Código, e após o surgimento dele, não obstante a dramaticidade do contexto em que ele nasceu, infelizmente, as infrações continuaram e continuam a ocorrer. Dessa forma, os mesmos autores ainda afirmam que por volta de 1960 começa a ser aceita a idéia de que os experimentos com seres humanos precisam ser revistos, ainda em sua fase de projeto, por uma comissão multidisciplinar.

De acordo com Palácios et al. (2002), a necessidade de regulamentar as pesquisas em humanos, de forma a proteger as populações a elas submetidas e a pouca influência do Código de Nuremberg sobre as práticas, estão entre as razões que levaram à publicação da chamada Declaração de Helsinque. No Brasil, o Conselho Nacional de Saúde (CNS) aprovou um documento que teve como objetivo criar parâmetros éticos para as pesquisas na área da saúde, a Resolução CNS 01 (1988). Posteriormente, esta foi substituída pela resolução CNS 196 (1996).

Segundo Araújo (2003):

[...] a partir da Resolução CNS 196 (1996) e das resoluções complementares, o desenvolvimento das pesquisas com seres humanos, no Brasil, tomou um novo rumo e os pesquisadores tiveram que se adaptar ou estão se adaptando a essa nova realidade.

\section{E ainda complementa:}

A Resolução CNS 196 (1996) define pesquisa com seres humanos como aquela "que, individual ou coletivamente, envolva o ser humano de forma direta ou indireta, em sua totalidade ou partes dele, incluindo o manejo de informações ou materiais". Essa definição éde fundamental importância, pois não restringe o conceito de pesquisa com seres humanos apenas àquelas realizadas nas ciências da saúde. Inclui toda modalidade de pesquisa que direta ou indiretamente envolva seres humanos e, mais, que o manejo de informações e a utilização de partes do corpo, como por exemplo, dentes, são consideradas pesquisa com seres humanos e devem seguir parâmetros éticos. (Araujo, 2003, p. 4).
É importante destacar que a Resolução CNS 196 (1996) é considerada uma recomendação ética e não uma lei. Contudo, por meio dela, já tem sido possível fiscalizar as pesquisas que têm sido feitas no país. Um exemplo é o fato de que os periódicos e os eventos científicos, nacionais e internacionais, têm solicitado a comprovação de que o trabalho foi aprovado previamente por um Comitê de Ética em Pesquisa ou CEP, que existe em cada instituição em que ela ocorre.

Ainda de acordo com Palácios et al. (2002), toda pesquisa que envolva direta ou indiretamente seres humanos é obrigada a ser analisada por um CEP. E, em alguns casos, deve ser avaliada por mais de um, como no caso dos estudos multicêntricos: o mesmo protocolo tem obrigatoriamente que ser analisado por tantos CEPs quantas instituições participarem da pesquisa. Estes são multidisciplinares quanto à sua composição e formados por pessoas das mais diversas áreas do conhecimento humano. Seu objetivo maior é preservar a integridade dos sujeitos, objetos da pesquisa científica, bem como apreciar previamente os projetos de pesquisa.

O princípio da autonomia deve ser assegurado no desenvolvimento de experimentos com seres humanos por meio da obtenção do consentimento livre e esclarecido dos sujeitos, objetos da pesquisa. Este representa um dos suportes éticos na execução deste tipo de pesquisa. Araújo (2003) afirma que o consentimento é o livre exercício da autonomia do sujeito voluntário.

Sendo assim, entra-se numa discussão sobre o que é necessário respeitar quando se lida com sujeitos humanos em pesquisas. Conforme a Resolução n. ${ }^{\circ}$ 016/2000 do Conselho Federal de Psicologia, existem algumas normas que devem ser seguidas. Dentre elas, está o Artigo $1^{\circ}$, que afirma que toda pesquisa em Psicologia que envolva seres humanos deve ser antes submetida a um Comitê de Ética, para ser analisada sua viabilidade.

Nesta ocasião, também é entregue um protocolo no qual estão detalhados os seguintes itens: os objetivos da pesquisa, a justificativa de sua relevância científica e social, os procedimentos a serem adotados e as questões éticas referentes ao consentimento informado e aos limites para o uso das informações com os meios de divulgação que serão utilizados.

No que se refere ao consentimento informado, a Resolução n. ${ }^{\circ}$ 016/2000 do CFP 
postula nos Artigos $4^{\circ}$ e $5^{\circ}$, sobretudo, que os psicólogos pesquisadores, em respeito à autonomia, deverão garantir, em suas pesquisas, que a participação é voluntária e que os participantes serão informados sobre os objetivos da pesquisa e o uso que será feito das informações coletadas e também que obterão o consentimento informado dos indivíduos a serem pesquisados como garantia de efetiva proteção dos participantes.

As recomendações do CFP (Resolução n. $\left.{ }^{\circ} 16 / 2000\right)$ também incluem que o participante da pesquisa seja informado dos riscos aos quais estará sujeito e da maneira pela qual os resultados serão divulgados, a fim de que o sujeito não seja exposto a danos quaisquer, o que é feito especialmente pelo seu Artigo $9^{\circ}$, que destaca o dever de todos os membros da equipe de pesquisa de conservar em sigilo as informações confidenciais obtidas, assim como proteger de riscos os participantes.

\section{METODOLOGIA}

\section{Sujeitos:}

Participaram desta pesquisa 9 (nove) professores, selecionados entre os que trabalham prioritariamente com pesquisa, bem como pela disponibilidade deles em participarem. Todos são docentes do Departamento de Psicologia da Universidade Federal de Santa Catarina.

\section{Local:}

As entrevistas foram realizadas no Departamento de Psicologia da Universidade Federal de Santa Catarina, na sala de cada respectivo professor, com exceção de um dos participantes que foi entrevistado na sala das pesquisadoras.

\section{Material:}

Para a realização da atividade, foi utilizado um gravador portátil, que servia como suporte para a gravação das entrevistas, para posterior transcrição com maior facilidade e fidedignidade. Foi usado um roteiro de entrevista com um cabeçalho sobre os objetivos da entrevista, bem como quatro (4) questões abertas sobre aspectos de ética a ressaltar para um iniciante. As questões propostas foram: quais aspectos éticos destaca como mais importantes em pesquisas com seres humanos; quais as principais recomendações que faz aos pesquisadores iniciantes; você tem alguma experiência que ilustre os aspectos éticos em pesquisas com seres humanos; você tem alguma sugestão de referência da literatura sobre ética em pesquisas com seres humanos.

\section{Procedimento:}

A coleta de dados durou cerca de dois (2) meses e aconteceu por meio de entrevistas, que foram agendadas previamente com os participantes, nas quais estes discorriam a respeito das questões centrais a respeito do tema. Entregou-se previamente o roteiro de questões para direcionar a entrevista com cada sujeito.

Posteriormente, deu-se o contato direto para a entrevista com cada participante. Estas duraram cerca de meia hora cada. As entrevistas foram submetidas à análise de conteúdo, separando-se, assim, dentro delas, os tópicos abordados, que constituíram os elementos para a construção dos resultados.

\section{RESULTADOS E DISCUSSÃO}

Os nove sujeitos da presente pesquisa incluíam quatro sujeitos do sexo feminino e cinco sujeitos do sexo masculino e serão identificados de E1 (entrevistado um) a E9 (entrevistado nove), a fim de facilitar a análise dos dados. Em todos os casos, as entrevistas se deram na ausência de outras pessoas que pudessem interromper ou perturbá-las. O fato de a entrevista ter sido precedida pela entrega das questões impressas também facilitou a interlocução. Ainda que em muitos aspectos todos os entrevistados viessem a indicar pontos fortes da ética de pesquisa com sujeitos humanos semelhantes, o destaque dado a cada ponto, bem como as situações vividas e relatadas foram bastante variadas e ricas. Assim, procura-se aqui apresentar os elementos comuns, bem como os destaques apresentados.

Para se chegar a uma boa orientação ética, é preciso que o pesquisador tenha clareza em relação ao que busca; quais são seus objetivos, 
qual objeto busca conhecer. Este conhecimento do objeto e dos objetivos buscados é que vai ajudar o pesquisador a ter clareza acerca de como esta busca por meio da pesquisa científica pode contribuir para o bem-estar biopsicossocial dos seres humanos. Assim, uma das questões prioritárias em ética dirigida à pesquisa é saber como a pesquisa que está sendo realizada pode contribuir para atender às necessidades biopsicosociais dos seres humanos. Aqui, na presente pesquisa, isso foi inquirido na primeira questão acerca de quais os aspectos éticos o entrevistado julga importante ressaltar aos pesquisadores iniciantes, tendo em vista contribuir para o atendimento das necessidades biopsicosociais dos seres humanos. Para o entrevistado três (E3), a primeira recomendação ética a ser atendida é a de que a pesquisa seja colocada como instrumento para atender às necessidades humanas, sendo esta preocupação inicial também externada por outro entrevistado, (E6). Este coloca a necessidade de uma reflexão que permita estimar os benefícios e compensações da pesquisa em relação aos seus riscos. Destaca ainda e especialmente que este exame seja realizado antes de se iniciar qualquer pesquisa.

Ainda para este entrevistado (E6): Algumas pesquisas, em vez de trazerem benefícios para a comunidade, podem trazer até prejuízos. Então isso tem que ser avaliado. Às vezes, a pessoa está preocupada em descobrir alguma coisa, mas com que isso vai contribuir mesmo?, indaga. Para ele, a revisão das questões de por quê? e para quê? da pesquisa que está proposta devem assegurar que seus objetivos sejam claros e explícitos, da mesma forma que quem está participando da pesquisa tem que saber quais são eles. Ainda complementa que:

[...] uma pergunta que se segue a este raciocínio é: estes objetivos como estão colocados podem ser compreendidos pelos sujeitos? Assim, se alguém está utilizando como sujeitos, crianças ou mesmo adultos: será que compreenderam os objetivos da pesquisa? Então, é importante que os objetivos sejam formulados por escrito e de maneira que os sujeitos consigam ler. E depois se pode perguntar para eles se compreenderam, e sempre que possível, propor que estes verbalizem qual o que foi proposto.
A fala do entrevistado nove (9) inicia-se por considerações semelhantes às destes dois outros entrevistados, destacando como orientação geral a preocupação com a relação que se estabelece, de modo que esta seja sempre de maximização de benefício em função dos custos para a pessoa. De acordo com o entrevistado, esta é uma observação de caráter mais geral que deve ser aplicada inclusive não só ao contexto de pesquisa, mas ao contexto mais amplo da atuação profissional de qualquer profissão, não só da Psicologia.

Ainda em resposta a esta questão, um dos aspectos éticos a ressaltar também foi a importância que tem para os sujeitos da pesquisa poderem decidir se aderem ou não a ela. Importa dar condições adequadas para esta decisão. $\mathrm{O}$ que se busca é o que se denomina consentimento esclarecido, que consiste no direito que o participante tem de saber do que trata a pesquisa: quais os objetivos buscados, quais os procedimentos adotados, como serão tratados os resultados, como será a comunicação da pesquisa, etc. É com base nestas informações que o sujeito dará seu consentimento ou não.

Em relação à segunda questão, acerca de quais recomendações devem ser feitas especificamente a estes pesquisadores iniciantes, cabe destacar a recomendação que se refere ao cuidado do pesquisador em situar a pesquisa que está sendo realizada. Conforme o entrevistado sete (E7):

Eventualmente um teste que se faça com crianças, testes sobre Piaget ou outros assuntos, ainda assim teste, precisa-ser deixar claro que são testes mais para os alunos (da Psicologia) do que para a pessoa que está sendo testada. $\mathrm{Ou}$ ainda, quem vai ganhar mais serão os alunos e não propriamente as crianças ao terem um resultado sobre o seu desempenho cognitivo: quem está aplicando também está aprendendo como fazer aquela atividade, portanto o ganho é seu.

O entrevistado ainda completa que ao esclarecer os objetivos do trabalho e deixar claro que não é propriamente para avaliar a pessoa, mas, principalmente, para o aluno-pesquisador ter domínio de uma técnica, é importante reiterar que os resultados obtidos podem às vezes ter 
algum grau de comprometimento, o que não significa necessariamente mau desempenho da pessoa, já que, entre os alunos que vão aplicar o teste, alguns se enrolam na sua aplicação. Como é que se pode dar um diagnóstico sobre uma atividade que se fez de forma tão tateante, e às vezes até inadequada? E se o problema não está na pessoa que é sujeito na atividade, mas na maneira como ela foi realizada?

Então isto tem que estar explícito para as pessoas que estão fazendo o teste, e com crianças, isto tem que estar mais claro ainda. Porque se tem uma atividade, elas logo perguntam se está certo ou se está errado. A pessoa tem que dizer que não tem certo ou errado, que é uma atividade na qual quem está aplicando está aprendendo sobre isto (E7).

À questão dos objetivos segue-se, de acordo com o entrevistado três (E3), como decorrência dos objetivos buscados, a questão da definição dos sujeitos da amostra. Certos assuntos que são objetos de pesquisa levam o pesquisador a selecionar sujeitos determinados, que são marcados: eles detêm informações importantes sobre o tema tratado, mas suas situações de vida podem ser extremamente difíceis, sua saúde pode ser precária, podem carregar estigmas sociais, etc. Exemplos de sujeitos assim podem ser os portadores de AIDS, DSTs, drogaditos, pessoas com câncer, vítimas de abuso, entre outras situações. Como ponto de partida: como pedir informações sem criar constrangimento e causar dor? Além da sensibilidade do pesquisador na forma de tratar seu sujeito e de abordá-lo, os entrevistados ressaltam a importância de os participantes de pesquisa poderem escolher se aderem ou não à pesquisa, e também, que eles possam escolher livremente se desejam ou não participar e a qualquer momento, mesmo com a pesquisa já em andamento, possam se recusar a continuar, como aponta o entrevistado dois (E2) nesta amostra.

Um aspecto importante quando se pede o consentimento do participante é que se tenha bastante claro o tipo de informação que vai ser solicitada dessa pessoa; pode-se eventualmente estar assustando-a, esta pode pensar que é algum tipo de experimento invasivo, que vai ter algum tipo de prejuízo, haverá algum sofrimento para si.
Então é importante que o pesquisador tenha bastante claro que tipo de dados ele vai solicitar do sujeito para que ele possa deixá-lo muito à vontade no sentido de fornecer informações. Assim, as recomendações sugeridas visam deixar bem clara a natureza do dado que vai ser solicitado ao participante. Isso é fundamental para que ele possa ter tranqüilidade e fazer um consentimento bastante claro, sem nenhum receio de que aquele dado vá prejudicálo, informa o entrevistado oito (E8).

Ao lado das questões mais gerais da ética das relações como destacado por alguns entrevistados (E1, E4, E8, E9) e falando mais especificamente do ponto de vista daquilo que é necessário observar em função da especificidade do problema de pesquisa e em função das características do instrumento de coleta de dados, o entrevistado nove (9) destaca alguns aspectos mais corriqueiros na pesquisa, como: nunca desenvolver um procedimento sem que a pessoa esteja plenamente consciente, realmente informada daquilo que será feito. Neste, plenamente significa: o que será feito; quando será feito; o que vai ser solicitado da pessoa - não exatamente o que, mas a natureza do que vai ser solicitado - quanto tempo ela terá para isto; se ela é livre para desistir em qualquer momento do procedimento ou não; qual é o ônus que acarreta o envolvimento dessa pessoa ou o consentimento dessa pessoa ao participar da pesquisa; e, também, uma garantia de que esta pessoa não terá nenhum tipo de prejuízo, nem no transcorrer da coleta de dados nem após, por conta dos dados obtidos na pesquisa ou pela participação.

Pode-se considerar que temas éticos emergentes nos discursos dos sujeitos em outras situações sociais, e em outras interações, seja o trabalho, amizades, deve ser usada integralmente na situação de pesquisa, como diz o entrevistado quatro (4). Segundo o entrevistado sete (E7):

A gente tem que ser ético não só quando trabalha. É preciso ética nas relações humanas, no cotidiano, no tratar com respeito ao nosso colega, ao nosso funcionário. Todas as nossas relações humanas devem ter um princípio ético que as orienta. A ética é uma questão básica e deve ser considerada sempre.

Nesse sentido, a abordagem ao sujeito da pesquisa é uma interação social como outras 
quaisquer, então a relação pesquisadorpesquisado deve ser uma relação pautada numa relação de respeito, de não discriminação racial, de não discriminação política (E4).

Ao conquistar a adesão do sujeito, o pesquisador recebe o encargo de resguardar a privacidade deste. O compromisso do pesquisador com o sigilo é uma condição sine qua non para que possa realizar pesquisa com humanos, como destacaram todos os entrevistados, pois ser um sujeito de pesquisa é oportunizar conhecimentos que são às vezes únicos; assim, o sujeito não deve ter como contrapartida para si nenhum ônus: nem que sua identidade seja conhecida, nem constrangimento e menos ainda formas de sofrimento, sejam estas físicas ou psíquicas. O pesquisador deve descaracterizar as informações em relação às suas fontes, dissolver a identidade de seus informantes, protegê-los no anonimato.

Ressalta o entrevistado quatro (4):

Não há pesquisa ou vontade científica que justifique causar como um efeito seu, algo que faça algum mal, dano moral, emocional ou físico às pessoas. Então, quando se pensa em trabalhar com Psicologia numa escola, e fazer uma determinada pesquisa, e se identifica a classe, desta forma se está de algum modo identificando o professor. Quem pegar aquele relatório, saberá qual a classe tratada e poderá identificar os sujeitos. Por isto é importante evitar qualquer tipo de identificação, ao realizar o relatório de pesquisa.

Outro aspecto importante em relação à ética na pesquisa é o retorno para os sujeitos que dela participam. Por exemplo, ao terminar o relatório de pesquisa, pode-se remeter para os sujeitos que fornecem as informações, os dados obtidos. Contudo, há um aspecto interessante: em vez de simplesmente pegar uma cópia do relatório técnico e mandar para eles, pode-se fazer um relatório especial que seja compreensível para os sujeitos, pois eles não têm obrigação nenhuma de compreender ou de analisar um relatório científico. É preciso um relatório especial de maneira que os sujeitos possam compreender os resultados e sua contribuição. Esta é uma questão ética importante. Ao pedir a autorização, um dos pontos é o compromisso de que se vai devolver aquelas observações, aqueles dados que foram obtidos. Depois de terminar o seu relatório, tem que se devolver os seus dados, num formato especial, numa linguagem compreensível, coloca o entrevistado oito (E8). Segundo o entrevistado sete (E7):

[...] muitas veres os pesquisadores vão lá, fazem a pesquisa e, no entanto, não devolvem nada, seja para a instituição, para os pais ou para a criança. Mesmo que seja alguma coisa reduzida - não precisa ser o relatório completo! Mas a devolução é importante, mesmo que sintéticapara aspessoas que participaram da atividade. A devolucão pode ocorrer não só de forma direta, mas também ao deixar alguns indicadores, telefone, email, para pessoa que quiser contato sobre o trabalbo, possa tê-lo.

Ainda em relação ao consentimento esclarecido, bem como aos esclarecimentos necessários pra obter a cooperação do sujeito, é interessante levantar questionamentos, como faz o entrevistado quatro (4): quando vamos a campo com uma hipótese, ou fazemos um experimento, como proceder para obter o consentimento esclarecido e ao mesmo tempo não produzirmos os resultados? Ou seja, se expormos todas as nossas hipóteses e considerações para o sujeito, podemos induzi-lo a responder de modo a atender nossos desejos. Esta é uma situação já estudada pela Psicologia Social. Como então informar sobre a pesquisa, sem criar viés? A informação sobre a pesquisa, ainda que verdadeira, deve ser algo geral e não tão detalhada, de modo que não vá invalidar as respostas dadas pelos sujeitos.

Outro aspecto destacado é sobre os riscos oriundos das tecnologias atuais. Conforme o entrevistado seis (E6):

Usamosfilmadoras, gravadores, microcomputadores, entre outros recursos, que nos ajudam a lidar com a pesquisa, mas que também oferecem riscos novos. O que pode acontecer se hakers invadirem estes arquivos que são confidenciais? Ou ainda, o que fazer após a compilação de dados? Os bolsistas e ajudantes que digitam os dados? Um dos nossos entrevistados que ouviu muitas histórias de vida em uma amostra de drogaditos, após a conclusão do trabalho devolveu para eles as fitas originais.

Ao estabelecer o contato com os possíveis sujeitos, são informações como estas, sobre o que está sendo estabelecido como responsabilidade de parte do pesquisador, em relação ao que fazer com os registros de informação, e também em relação à divulgação 
da pesquisa, que as tecnologias atuais exacerbam.

Para o entrevistado cinco (5), uma das boas novidades que ocorreram nos anos 90 foi o desenvolvimento da bioética: certa regulamentação de ética em pesquisa envolvendo não apenas seres humanos mas organismos vivos e a própria relação com a natureza. Uma pauta ética para orientar a pesquisa agora passa pela bioética e está sendo objetivamente materializada em torno de regulamentos.

A importância de exigências legais foi destaque nas falas de cinco entrevistados (E1, E4, E5, E6 e E7). O fato de alguém ter que apresentar um projeto de pesquisa a uma comissão ética da Instituição, como ocorre nas Instituições de Ensino Superior (IES), e de universidades como a UFSC e, além disso, deste ser acompanhado, ou seja, o projeto precisa de autorização, bem como a exigência que as revistas fazem hoje em dia de que os relatos de pesquisas com seres humanos, para ser publicados, tenham aprovação do comitê de ética, tudo isso constitui uma pauta concreta para se trabalhar em pesquisa, não só com seres humanos. O entrevistado sete (7) complementa, dizendo que inclusive bolsas são dadas em função disso. Esta pauta, nas palavras do entrevistado cinco (E5), é um grande avanço. Os principais aspectos éticos são colocados pela pauta da bioética. Para o campo da Psicologia, há que se destacar, além da pauta bioética, as questões do sigilo, da preservação de identidades, o cuidado no tratar com as pessoas, para não manipular e não conduzir as informações, e de evitar abuso de poder, para não abusar da relação, que são algumas questões fundamentais na relação com seres humanos e que precisam ser observadas.

De acordo com as colocações do entrevistado nove (9), é mais raro na pesquisa em Psicologia que os sujeitos tenham que experimentar drogas, por exemplo, e que sejam cobaias de alguma coisa que eles tenham que ingerir, injetar, usar, ou seja, procedimentos que são muito invasivos e assim fiquem expostos a algum risco do ponto de vista biológico. Geralmente, na Psicologia, os procedimentos são constituídos por entrevistas; respostas a questionários e a participação eventual em alguma observação ou experimentação nas quais seus comportamentos sejam motores, ou de interação, ou mesmo a fala sejam objeto de investigação.

Ainda ressalta que pode ser mais útil adotar os instrumentos mais cotidianos e mais comuns de obtenção de dados. No caso da observação direta, por exemplo, a pessoa que está sendo observada precisa saber disso. Para o entrevistado, isso é ponto pacífico, ainda que existam casos, raros, em que a pessoa não pode saber do que se trata, pois isso interferiria nos dados obtidos. Por exemplo, em situações de interação, nas quais o fato de se ter lá uma câmera seguindo o sujeito, pode alterar brutalmente o comportamento que se tem. Nesse caso exatamente, o fato de saber que se está sendo observado é a sua própria variável independente, e o saber ou não saber faz a diferença fundamental para o experimento, para o seu procedimento de pesquisa. Caso se tenha uma pergunta deste tipo, a pessoa não pode saber que está sendo observada.

À exceção destes casos especiais, nos demais deve haver a concordância do sujeito e este deve saber que está sendo observado, reafirma o entrevistado nove (E9), tratando de aspectos semelhantes aos já apontados pela entrevistado quatro (4), no que se refere a certas situações em que a forma da esclarecer o sujeito deve ser muito cuidadosa, para não inviabilizar a pesquisa. Em relação ao consentimento, no caso de crianças, ele deve ser obtido por meio do contrato com os pais, ou das pessoas que são responsáveis: escola, professores médicos, profissionais que cuidam da criança e, na ausência deles, com as pessoas que respondem por ela.

Acerca da explicação dos objetivos do trabalho, é preciso considerar que ao dizer qual é o objetivo da investigação, pode-se já estar causando interferência nos dados. O entrevistado quatro (E4) afirma que:

\section{Neste caso se faz opsão por contar um objetivo que seja mais geral. O sujeito não precisa da especificidade do objetivo. Para que apessoapossa dar seu consentimento, é suficiente que tenha informaçoes sobre possiveis consequiencias para si, bem como, que lhe permitam escolber entre participar ou não.}

Especificamente em relação aos iniciantes da pesquisa, as recomendações, como já apontadas acima, vão de ênfase à preparação por meio do acesso à literatura sobre o assunto, aí incluindo as normas sobre ética de pesquisa, algumas aqui também já referidas, acompanhados pelo diálogo com o professor orientador: na medida em que o iniciante tem clareza da condição 
de aprendizagem que se encontra, isso contribui para lhe conferir a habilidade (ou humildade) para lidar com a situação.

Considerando os aspectos positivos que a Resolução 196 traz em relação às considerações éticas no campo da pesquisa, saudado como um marco por vários dos sujeitos aqui abordados, também se precisa levar em conta certas características que vivemos no país, que pressionam no sentido contrário, como bastante enfatizado pelo entrevistado quatro (E4), a seguir:

Pode-se tomar por exemplo, a televisão: não se tem nenhum controle sobre ela, que tem um papelimportante para desenvolvercertos valores e colocá-los como referência: é a idéia de que o mundo é dos espertos, que a gente deve buscar a maior quantidade de dinheiro possível, ter as melhores coisas, a qualquer preço etc. Os efeitos se percebem na visão da juventude: é uma visão que se torna completamente antiética, impregnada de valores como a corpolatria, que é a idolatria do corpo a qualquer custo e essa perpassa a maneira como as pessoas tratam o corpo, a vida, o sucesso, etc. que se torna uma mercadoria em todos os sentidos. Não só em relação aos profissionais do sexo. Mas, no mundo do espetáculo, da cultura. Para homens e para as mulheres também...

Reconhecendo estas influências sobre a juventude, as discussões sobre ética nas relações humanas, em geral, ao lado daquelas relacionadas à pesquisa, tornam-se mais do que nunca muito oportunas.

Uma questão que também é fundamental (embora todas as demais também tenham seu papel ao assegurar os direitos dos participantes de pesquisas) não apenas nas que envolvem seres humanos, mas norteando as relações humanas em geral, e que foi citada pela metade dos participantes, tem relação ao respeito. De acordo com Pessini e Barchifintaine (2000), "o respeito está entre os três princípios básicos que norteiam a pesquisa envolvendo seres humanos, os quais são o respeito pela pessoa, a beneficência e a justiça”" (p. 142). A categoria respeito possui duas considerações importantes: respeito pela autonomia, na qual as pessoas sejam respeitadas por sua autodeterminação em poder escolher aquilo que desejam fazer; e o respeito pelas pessoas com sua autonomia modificada ou alterada, devendo ser protegidas de abusos ou maus-tratos.

Acerca do consentimento, Muñoz e Fortes (1998) declaram que para que se tenha uma decisão autônoma, é necessário que a pessoa tenha informações adequadas e que possa compreendêlas, a fim de aceitar ou recusar participar, sendo que este não pode ser obtido por via de nenhum tipo de prática coativa ou por quaisquer práticas manipulativas. Sobre o sigilo, Zanella (2003) assegura que é necessário tomar uma série de precauções, a fim de que o participante não sofra o menor desconforto possível no âmbito biopsicossocial. As questões relativas ao anonimato, consentimento livre e esclarecido e sigilo são corroboradas na literatura apresentada anteriormente, principalmente por meio das idéias de Araújo (2003), que coloca, por exemplo, que o consentimento livre e esclarecido é uma demonstração da autonomia do participante.

Revela-se aqui, a partir das respostas obtidas de cada um dos participantes, a importância de um aparato legal e regulatório em pesquisas com seres humanos. Dessa forma, é possível assegurar um maior controle das atividades que são desenvolvidas nesta área e um melhor suporte legal àquelas pessoas que estão se disponibilizando a participar de pesquisas em geral, sem deixar de citar é claro um maior respeito à vida e às pessoas, assim assegurado.

A terceira questão pedia aos entrevistados exemplos de questões éticas que tenham ocorrido em situações de pesquisa. O primeiro exemplo é relatado pelo entrevistado quatro (4). Segundo ele, é freqüente no curso de Psicologia que os alunos sejam incentivados a realizar pesquisas. Isso pode ser extremamente complicado e criar situações graves, por falta de compreensão das questões éticas, o que pode ser fácil de acontecer quando os alunos são de fases iniciais, sem muita experiência, e também porque é bem difícil para um professor fazer uma boa supervisão quando tem sob sua responsabilidade uma classe com 40 alunos.

Um exemplo negativo disso aconteceu há alguns anos, em que alunos do curso abordaram as chamadas profissionais do sexo, que foram gravadas e filmadas, tendo, assim, suas identidades desveladas. Mais tarde, quando elas foram abordadas em outra pesquisa, agora não mais por alunos, recusaram-se a colaborar em função do ocorrido.

Já um exemplo positivo oferecido por este entrevistado aconteceu quando o objeto de 
estudo era a violência e agressão contra crianças, bem como o conceito e representação que dela faziam. Como abordar isso com elas, quando a própria reminiscência do fato já causaria dor por si só? Tendo em vista os objetivos buscados de conhecer melhor esta situação, o procedimento adotado não foi o de abordar individualmente crianças vítimas de agressão e violência. A partir de um levantamento dos bairros em que os abusos eram registrados com maior freqüência, decidiu-se por ir a uma escola e pedir para uma amostra de alunos que fizesse uma manifestação sobre estas situações, por meio de uma redação ou desenho. Este procedimento possibilitou explorar o assunto, sem exacerbar os sentimentos de dor que o cercam.

Como orientação para que sejam evitados casos parecidos ao relato acima, em que os sujeitos de pesquisa, as profissionais do sexo, foram usadas apenas como fonte de informação e não receberam qualquer contrapartida à investigação, devem valer as normas de ética, e ao lado delas:

O pesquisador, especialmente o iniciante, deve buscar esclarecimento na literatura: ele deve fazer uma boa revisão sobre o assunto antes de ir a campo, o que o ajuda nas suas definições. Além disto, deve recorrer a quem o está orientando, buscando apoio para tocar a pesquisa. É muito importante ele buscar apoio e reconbecer que ele não tem experiência, que a inexperiência dele pode ser problemática, e também, que é muito importante para ele iniciar bem a pesquisa, como destaca o entrevistado (E4).

Outro exemplo positivo refere-se a uma turma com alunos da $1^{\mathrm{a}}$ fase de Psicologia que teve como atividade entrevistar psicólogo. Aí as recomendações para eles, segundo o entrevistado 1 (E1), foram:

Tomem alguns cuidados. Vocês vão gravar a entrevista. Então peçam permissão para gravar. A pessoa pode não concordar. Depois o seguinte: o nome, a pessoa pode dizer 'eu dou a entrevista, mas não quero que men nome seja divulgado. Então, o que deve ser destacado mais que nunca para o entrevistado, são alguns cuidados de preservação; de manipulação, de evitar abuso de poder e deixar as regras do jogo bem claras. Estes cuidados são muito importantes não só numa pesquisa, mas nos estágios curriculares também.

Como diz o entrevistado sete (E7): É preciso dizer olha, nós vamos fazer isso, o método é esse, o objetivo é esse, as proteções são essas, os riscos são esses... Isto é a questão do consentimento. É a pesquisa na qual o participante está consciente de todos os principais aspectos dela. Para este sujeito aqui abordado, isso é realmente fundamental e isso representa um grande avanço na nossa pesquisa nos últimos dez anos.

E por fim, na quarta questão, era pedido aos participantes referências acerca do tema. Todas as falas fizeram menção explícita à legislação em vigor, a Resolução 196, sendo que em duas delas foi ressaltado o seu lado positivo, ao passo que um dos entrevistados ressaltou contradições que esta legislação deixa às investigações psicológicas e sociais, na medida em que toma como referencial apenas as investigações médicas, de uso de fármacos e outras semelhantes, que não abordam mais de perto as questões relacionadas às situações em que são realizadas as investigações de conteúdo mais social ou psicológico.

Nesse sentido, o Código de Ética do Conselho Federal (e Regionais) de Psicologia serve como uma proposta importante. Esse código, no entanto, não é específico para pesquisa e também é um código profissional para psicólogos. Um dos entrevistados destaca ainda que as exigências legais relativas aos procedimentos éticos podem tomar um caráter burocrático por suas exigências, como milhares de papéis que precisam ser assinados (E4), tais como aqueles com a autorização de cada sujeito.

\section{CONSIDERAÇÕES FINAIS}

Após o término das entrevistas e do tratamento das informações, pôde-se concluir que as respostas às questões oferecidas pelos participantes da pesquisa, em muitos aspectos, mostraram-se variadas e diversas. Contudo, uma quase unanimidade declarou que as atitudes mais importantes para a condução de pesquisas com seres humanos norteiam os quatro aspectos relacionados a seguir: o consentimento livre e esclarecido, onde o participante deve ter claro todas as etapas da pesquisa, qual será o seu papel dentro dela, devendo então concordar livremente ou não em participar; o sigilo, uma segurança ao participante de que as informações que serão fornecidas por ele serão mantidas em segredo; 
com esta questão, entra o anonimato, garantia esta de preservação da identidade dos participantes; e a devolução, para que o sujeito que se dispôs a participar dos experimentos possa receber um retorno daquilo que o pesquisador pôde descobrir.

É de extrema importância que os pesquisadores respeitem estes quatro princípios básicos que permeiam a pesquisa com seres humanos. Dessa forma, uma série de malentendidos e situações constrangedoras, que muito ocorrem na atualidade, pode ser minimizada. Também uma atitude ética perante as pessoas que são convidadas a participar de pesquisas faz com que o campo não se feche aos novos pesquisadores que poderão vir trabalhar em pesquisas ou temas com amostras semelhantes.

Também se revelou importante a organização de uma legislação que melhor se aplique às pesquisas com seres humanos, especialmente na área de Psicologia e que uma maior quantidade de informações seja desenvolvida nesta área, possibilitando, assim, um melhor subsídio teórico àqueles que estão ingressando nesta prática. Vale ressaltar que materiais específicos para as áreas da Saúde ou até mesmo direcionados à Medicina são insuficientes aos pesquisadores, por exemplo, que necessitam ir a campo pesquisar, porém não são da área. A questão de linguagem e do vocabulário são dois fatores que precisam ser adaptados aos diversos contextos, não se limitando apenas a algumas áreas do conhecimento.

Dessa forma, se observadas as idéias relacionadas acima, pode-se garantir uma prática mais ética não apenas para os estudantes que estão iniciando a pesquisa, mas também para os profissionais que fazem desta uma prática diária.

\section{REFERÊNCIAS}

Araujo, L. Z. S. (2003). Aspectos éticos da pesquisa científica. Pesquisa Odontológica Brasileira, 17, Recuperado em set 24 2004, da SciELO (Scientific Electronic Library Online): www.scielo.br/ scielo.php?script $=$ sci_arttext\&pid $=\mathrm{S} 1517$ 74912003000500009\&lng=pt\&nrm $=$ iso

Beecher, H. (1966). Ethics and clinical research. NEnjJMed., 274. Recuperado em may 03, 2004 da SciELO (Scientific Electronic Library Online): www.scielosp.org/ scielo.php?script=sci_arttext\&pid $=\mathrm{S} 14138123200$ $8000200011 \& \operatorname{lng}=$ en\&nrm $=$ iso...

Conselho Federal de Psicologia (2000). Resolução $\mathrm{n}^{\circ}$. 016/2000. Recuperado em Abr. 26, 2004, da Pol (Psicologia Online): www.cfp.org.br

Conselho Nacional de Saúde (1996). Resolução 196. Recuperado em Maio 03, 2004, da (PróReitoria de Pesquisa e graduação da Universidade federal de Uberlândia, MG. Online): www.propp.ufu.br/cep/Reso196.doc.

Costa, S., \& Diniz, D. (2001). Bioética: Ensaios. Brasília: Letras livres.

Ferreira, A. B. de H. (2004). Novo Aurélio: Dicionário da língua portuguesa. Curitiba: Positivo.

Hossne, W. S., \& Vieira, S. (1995) Experimentação com seres humanos: Aspectos éticos. In M, Segre, \& C., Cohen. (Org.). Bioética. São Paulo: EDUSP.

Muñoz D., \& Fortes P. A. (1998). O princípio da autonomia e o consentimento livre e esclarecido. In S. I., Costa,V., Garrafa. \& G., Oselka. (Org.). Iniciação à Bioética. Brasília, Conselho Federal de Medicina.

Palacios, M.; Rego, S. \& Schramm, F. R. (2002). A regulamentação brasileira em ética em pesquisa envolvendo seres humanos. In: R. M., Machado, D. M., Carvalho, C. K., Block, R. R Luiz, \& G. L., Werneck, (Org.). Epidemiologia. São Paulo, Atheneu.

Pessini, L., \& Barchifontaine, C. P. (2000). Problemas atuais de Bioética. São Paulo: Loyola.

Zanella, A. V. (2003). Reflexões sobre pesquisa em psicologia, método(s) e alguma ética. In A. V., Zanella.(1997). Ética e paradigmas na psicologia social. (pp. 122-134). Porto Alegre: ABRAPSO Regional Sul.

Recebido: 11/06/2007 Received: 06/11/2007

Aprovado: 03/03/2008 Approved: 03/03/2008 